\title{
A Contribution to the Application of Near-Infrared Spectroscopy for Tablet Analysis: Metformin Hydrochloride Tablets Case Study
}

\author{
L. MARIĆ, I. HOMŠEK
}

R\&D Institute, Galenika a.d., Batajnički drum b.b., 11080 Belgrade, Serbia

E-mails: razumpolze@gmail.com (L.Marić), irena.homsek@gmail.com (I. Homšek)

Sci Pharm. 2010; 78: 574

doi:10.3797/scipharm.cespt.8.LPAT03

\begin{abstract}
Near-infrared spectroscopy (NIRS) is a rapid and nondestructive analytical method. The use of near-infrared spectroscopy in the pharmaceutical industry has been rapidly increasing over the past decade, with particular interest in the analysis of solid dosage forms, such as tablets and capsules [1]. This article describes use of NIR spectroscopy to determine of content the active pharmaceutical ingredient (metformin hydrochloride) in tablets, as well as strength tablets. Our goal is to create a necessary basis of spectral data and develop an optimal chemometric models that will later be transferred and used for monitoring the process. The calibration set was made up of 100 laboratory and 180 production samples in which the content of the active ingredient varied from $90 \%$ to $110 \%$ of the declared value. The set of calibration samples, used for determination of the tablet hardness, included 70 laboratory and 70 production samples, which were compressed using four levels of compression force. The API content is determined by the validated HPLC method, while Erweka hardness tester was used to determine tablet hardness. NIR spectra analysis by using method of partial least squares [2]. The best result for drug content determination was obtained for the raw spectrum, where the coefficient of correlation for calibration model was 0.99945, RMSEC 0.552, and RMSEP 0.570 , with seven factors used. The model which gave the best results for the tablet hardness determination was obtained by second-derivative spectra (coefficient of correlation: 0.99616, RMSEC: 0.506 and RMSEP: 0.841).

According to the obtained results, it was concluded that both models ensured a high coefficient of correlation as well as low level of error of the calibration model and prediction. It can be concluded that NIR spectroscopy, a rapid and nondestructive technique, is a powerful tool that can be easily implemented, with appropriate technical solutions, in the production process, thus ensuring its on-line or in-line monitoring.
\end{abstract}

[1] Reich G. Near-infrared spectroscopy and imaging: Basic principles and pharmaceutical applications. Adv Drug Deliv Rev. 2005; 57: 1109-1143. doi:10.1016/j.addr.2005.01.020

[2] Adams MJ. Chemometrics in Analytical Spectroscopy, Royal Society of Chemistry, Cambridge, UK, 1995. 